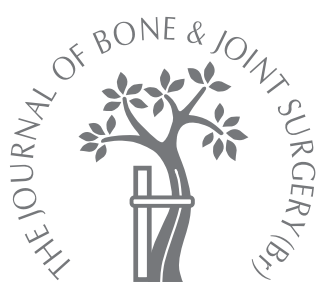

J. S. Lee,

K. T. Suh,

I. S. Eun

From Pusan National

University School of

Medicine, Busan,

South Korea

\title{
Polymorphism in interleukin-6 gene is associated with bone mineral density in patients with adolescent idiopathic scoliosis
}

Low bone mass and osteopenia have been described in the axial and peripheral skeleton of patients with adolescent idiopathic scoliosis (AIS). Recently, many studies have shown that gene polymorphism is related to osteoporosis. However, no studies have linked the association between IL6 gene polymorphism and bone mass in AIS. This study examined the association between bone mass and IL6 gene polymorphism in 198 girls with AIS. The polymorphisms of IL6-597 G $\rightarrow$ A, IL6-572 G $\rightarrow$ C and IL6-174 G $\rightarrow$ A and the bone mineral density in the lumbar spine and femoral neck were analysed and compared with their levels in healthy controls. The mean bone mineral density at both sites in patients with AIS was decreased compared with controls ( $p=0.0022$ and $p=0.0013$, respectively). Comparison of genotype frequencies between AIS and healthy controls revealed a statistically significant difference in IL6-572 $G \rightarrow C$ polymorphism $(p=0.0305)$. There was a significant association between the IL6-572 $\mathrm{G} \rightarrow \mathrm{C}$ polymorphism and bone mineral density in the lumbar spine, with the CC genotype significantly higher with the GC $(p=0.0124)$ or GG $(p=0.0066)$ genotypes.

These results suggest that the IL6-572 $\mathrm{G} \rightarrow \mathrm{C}$ polymorphism is associated with bone mineral density in the lumbar spine in Korean girls with AIS.

The aetiology and pathogenesis of adolescent idiopathic scoliosis (AIS) remain unclear. The aetiology is believed to be multifactorial, including such factors as growth, hormonal secretion and gravity. ${ }^{1-9}$ However, none of these parameters has been shown individually to play a causative role.

Burner, Badger and Sherman ${ }^{10}$ first noted an association between osteopenia and AIS using the Singh index. ${ }^{11}$ Generalised low bone mass and osteopenia in the axial and the peripheral skeleton have been described in AIS ${ }^{12-16}$ along with abnormal histomorphometric bone cell activity in bone biopsies. ${ }^{17}$ As the low bone mass in AIS patients is likely to persist into adulthood, ${ }^{12}$ there is increasing concern that adolescents with idiopathic scoliosis might have a lower peak bone mass, thereby increasing the risk of osteoporosis and related complications in later life. ${ }^{12,13}$ However, the precise mechanism and causes of bone loss in AIS have not been identified.

Osteoporosis is defined as a reduction in the microarchitecture of bone, resulting in an increase in fragility and the risk of fracture. It is a complex disorder, with interactions between environmental and genetic factors. The latter account for $50 \%$ to $80 \%$ of the inter-individual variability in bone mineral density (BMD) and several studies have demonstrated a relationship between polymorphisms of candidate genes with a decrease in BMD and an increased risk of fracture. ${ }^{18-23}$

Several studies have suggested that immunological factors such as interleukins and tumour necrosis factors might influence the development of osteoporosis. Interleukin-6 (IL-6) is a multifunctional cytokine essential in the differentiation and function of osteoclasts ${ }^{24,25}$ and IL-6 and its receptor are possible pathogenic factors in conditions associated with bone loss. ${ }^{24,25}$ Clinical studies have shown that IL-6 mRNA expression in bone is enhanced in $95 \%$ of patients with osteoporotic vertebral fracture but in only $50 \%$ of post-menopausal controls. ${ }^{24}$ Therefore, the genes of any component of IL-6 might be candidates for osteoporosis. Some investigators have evaluated the association between IL- 6 gene polymorphisms and BMD in post-menopausal women, ${ }^{26-31}$ but there are no reports linking the association between bone mass in patients with AIS and IL-6 gene polymorphism. We examined the association between bone mass in girls with AIS and IL-6 gene polymorphism and compared these with their levels in healthy controls. 


\section{Patients and Methods}

We enrolled 198 girls with a mean age of 12.5 years $(11.1$ to 13.9 ), newly diagnosed with AIS and 120 healthy girls recruited from routine school screenings, with a mean age of 12.7 years (11.0 to 13.9). The diagnosis of AIS was confirmed through a detailed medical history, physical examination and standard radiographs. The year since menarche and the Risser sign were also evaluated. Those receiving any form of treatment for scoliosis were excluded. Girls with a history of congenital deformities, neuromuscular disease, endocrine disease, skeletal dysplasia, connective tissue abnormalities, mental retardation, inflammatory diseases and use of medication known to affect bone metabolism were also excluded. All subjects and their parents gave informed consent before participating in the study, which was approved by the Clinical Research Ethics Committee of the university and hospital.

For the evaluation of scoliosis, normal standing wholespine anteroposterior radiographs were taken for each patient at their first presentation, using a standard technique to measure the Cobb angle. If more than one curve was found, the most severe was selected for the measurement. Curves $<10^{\circ}$ were excluded.

Anthropometric measurements included height and weight. For the patients with AIS, the corrected height was derived from Bjure's formula $(\log y=0.011 x \times 0.177$, where $y$ is the loss of trunk height $(\mathrm{cm})$ due to the deformed spine and $x$ is the greatest Cobb angle of the primary curve). ${ }^{13}$ The body mass index (BMI) was determined by dividing the weight $(\mathrm{kg})$ by the square of the uncorrected height $\left(\mathrm{m}^{2}\right)$.

The BMD of the lumbar spine and that of the neck of the non-dominant proximal femur were measured by dualenergy X-ray absorptiometry (DEXA, XR-36; Norland Corp., Fort Atkinson, Wisconsin). The lumbar BMD was measured in L1-4 in the anteroposterior view. The curvature might present difficulties in measuring the spinal BMD reliably and in order to minimise this problem, the level of rotation in patients with AIS was determined by prescanning the spine and measuring the lumbar spine BMD in the neutral position. ${ }^{15,32}$

For the measurement of biochemical markers of bone turnover, blood samples were collected between 8:00 am and 10:00 am after an overnight fast. The samples of plasma and serum were analysed in a routine laboratory using standard procedures according to the specifications of the manufacturers. Osteocalcin in heparinised plasma was measured by a solid-phase two-site chemiluminescent enzyme-labelled immunometric assay (Immulite Osteocalcin, Diagnostic Product Corporation, Los Angeles, California). Serum alkaline phosphatase was measured by radioimmuno assay (Tandem-R Ostase, Beckman Coulter, Fullerton, California). Serum $25(\mathrm{OH}) \mathrm{D}_{3}$ and $1,25(\mathrm{OH})_{2} \mathrm{D}_{3}$ levels were measured by radio immuno-assay (RIA) using the IDS (Immunodiagnostic System Limited, Boldon, United Kingdom). The intra- and inter-assay variabilities for $25(\mathrm{OH}) \mathrm{D}_{3}$ and $1,25(\mathrm{OH})_{2} \mathrm{D}_{3}$ are $<10 \%$.
For genotyping the genomic DNA was extracted from the peripheral blood leucocytes using a QIAamp DNA blood kit (Qiagen GmbH, Hilden, Germany). The polymorphic regions of the IL-6 gene were amplified by polymerase chain reaction (PCR) with the specific forward primers (GCAAAGTCCTCACTGGGAGGA for -597 $\mathrm{G} \rightarrow$ A, GCAAAGTCCTCACTGGGAGGA for $-572 \mathrm{G} \rightarrow \mathrm{C}$ and AATGACGACCTAAGCTGCAC for $-174 \mathrm{G} \rightarrow \mathrm{C}$ ), and with the specific reverse primers (GGGCTGCGATGGAGTCAGA for $-597 \mathrm{G} \rightarrow$ A, GGGCTGCGATGGAGTCAGA for $-572 \mathrm{G} \rightarrow \mathrm{C}$ and TTGATAAATCTTTGTTGGAGGGTG for $-174 \mathrm{G} \rightarrow \mathrm{C})$. The PCR was carried out in a mixture of 1.25 pmol of each primer, $50 \mathrm{ng}$ genomic DNA, $250 \mathrm{M}$ dNTPs and $0.15 \mathrm{U}$ TaqMan nuclease method (Applied Biosystems, Foster City, California) provided by the manufacturer. Amplication was carried out in a GeneAmp PCR system 9700 thermal cycler (Applied Biosystems). Their sequences were determined by cycle sequencing using an ABI PRISM Bigdye Terminator Cycle Sequencing Ready Reaction kit (Applied Biosystems) on an automated DNA sequencer (ABI PRISM 310, Perkin Elmer Applied Biosystems, Foster City, California).

Statistical analysis. This was performed using SPSS 11.5 software for Windows (SPSS Inc., Chicago, Illinois). The data are expressed as the mean (SD). The Hardy-Weinberg equilibrium was tested for each single nucleotide polymorphism (SNP) and group of participants using the chisquared test. The frequency distributions of genotypes in the AIS and healthy controls were compared for each SNP studied using the chi-squared test. The groups were compared using a $t$-test, ANOVA and non-parametric KruskalWallis test, where appropriate. A p-value $<0.05$ was considered significant.

\section{Results}

The mean Cobb angle for patients with scoliosis was $24.8^{\circ}$ $\left(16^{\circ}\right.$ to $\left.69^{\circ}\right)$. A total of $16.7 \%(n=33)$ of girls with AIS were premenarchal when their curvature was detected and 165 were post menarchal, with a mean of 1.4 years $(0.2$ to 4.0) since menarche. In the AIS group, $76.8 \%(n=152)$ were of Risser grades $0(n=42), 1(n=59)$, and $2(n=51)$. There were 131 thoracic, 47 double, ten thoracolumbar and ten lumbar curves.

The genotype frequencies of all SNPs studied were determined by screening DNA samples from 318 subjects (AIS group $=198$, control $=120$ ). The genotype frequencies of the subgroups are summarised in Table I. The genotype frequency distributions of all three polymorphic SNPs were in Hardy-Weinberg equilibrium. Comparison of genotype frequencies between patients with AIS and controls revealed statistically significant differences in IL6-572 $\mathrm{G} \rightarrow \mathrm{C}$ polymorphism ( $p=0.0305)$. IL6-597 $\mathrm{G} \rightarrow \mathrm{A}$ and IL6-174 $\mathrm{G} \rightarrow \mathrm{C}$ were totally linked together and showed very rare allele frequencies in both groups.

The investigations for the two groups are presented in Table II. For each genotype, the difference in age, BMI, 
Table I. Genotype frequency distributions in patients with adolescent idiopathic scoliosis (AIS) and healthy controls

\begin{tabular}{cccc}
\hline Genotype & AIS $(\mathbf{n}=\mathbf{1 9 8})$ & Controls $(\mathbf{n}=\mathbf{1 2 0})$ & p-value \\
\hline-597 G $\rightarrow$ A & 197 & 119 & \\
GG & 1 & 1 & \\
GA & 0 & 0 & 0.0305 \\
AA & & & \\
-572 G $\rightarrow$ C & 130 & 67 & \\
GG & 64 & 44 & \\
GC & 4 & 9 & \\
CC & & & \\
-174 G $\rightarrow$ C & 197 & 119 & \\
GG & 1 & 1 & \\
GA & 0 & 0 & \\
AA & & & \\
\hline
\end{tabular}

Table II. Genotype frequency distributions in adolescent idiopathic scoliosis (AIS) and healthy controls

\begin{tabular}{|c|c|c|c|}
\hline & AIS $(n=198)$ & Controls $(n=120)$ & p-value \\
\hline Age (yrs) & $12.5(11.1$ to 13.9$)$ & $12.7(11.0$ to 13.9$)$ & 0.1766 \\
\hline $\mathrm{BMI}^{*}$ & $18.0(15.0$ to 23.9$)$ & $18.2(14.7$ to 29.3$)$ & 0.5051 \\
\hline $\mathrm{cBMI}^{\dagger}$ & 17.7 (14.8 to 23.6 ) & $18.2(14.7$ to 29.3$)$ & 0.0582 \\
\hline $25(\mathrm{OH}) \mathrm{D}_{3}(\mathrm{ng} / \mathrm{ml})$ & 14.3 (5.2 to 26.7$)$ & 13.4 (6.6 to 23.4$)$ & 0.5700 \\
\hline $1,25(\mathrm{OH})_{2} \mathrm{D}_{3}(\mathrm{ng} / \mathrm{ml})$ & $79.4(29.4$ to 127.5$)$ & 81.0 (32.0 to 132.3$)$ & 0.3833 \\
\hline Osteocalcin (mg/L) & 25.6 (7.3 to 43.0 ) & $21.8(6.0$ to 42.1$)$ & 0.3301 \\
\hline Alkaline phosphatase (mg/L) & 12.7 (5.9 to 21.1$)$ & 11.4 (5.0 to 21.7 ) & 0.3725 \\
\hline Lumbar spine $\mathrm{BMD}^{\ddagger}\left(\mathrm{g} / \mathrm{cm}^{2}\right)$ & 0.717 (0.619 to 0.879$)$ & $0.737(0.619$ to 0.897$)$ & 0.0022 \\
\hline Femoral neck BMD $\left(\mathrm{g} / \mathrm{cm}^{2}\right)$ & $0.705(0.615$ to 0.835$)$ & $0.725(0.613$ to 0.908$)$ & 0.0013 \\
\hline
\end{tabular}

Table III. Bone mineral density in different genotype subgroups of adolescent idiopathic scoliosis

\begin{tabular}{|c|c|c|c|c|}
\hline$-572 G \rightarrow C$ & GG & GC & CC & p-value \\
\hline \multicolumn{5}{|l|}{ BMD $^{*}$} \\
\hline Lumbar spine & 0.713 (0.619 to 0.854$)$ & 0.720 (0.631 to 0.879$)$ & $0.804(0.731$ to 0.861$)$ & 0.0159 \\
\hline Femoral neck & $0.706(0.629$ to 0.835$)$ & $0.704(0.615$ to 0.807$)$ & $0.708(0.690$ to 0.732$)$ & 0.8865 \\
\hline
\end{tabular}

* BMD, bone mineral density

cBMI and biochemical markers between genotype subgroups were compared in AIS and the healthy controls. No statistically significant differences were identified. The mean lumbar spine and femoral neck BMD in patients with AIS were decreased compared with those controls ( $\mathrm{p}=0.0022$ and $\mathrm{p}=0.0013$, respectively).

The IL6-572 $\mathrm{G} \rightarrow \mathrm{C}$ polymorphism was significantly associated with lumbar spine BMD but not with femoral neck BMD (Table III). The former in AIS patients with the CC genotype was significantly higher than in the AIS patients with the GC ( $\mathrm{p}=0.0124)$ or $\mathrm{GG}$ $(\mathrm{p}=0.0066)$ genotypes. However, the loci IL6-597 $\mathrm{G} \rightarrow \mathrm{A}$ and IL6-174 G $\rightarrow$ A were not analysed statistically because the rare allele frequencies in the AIS group were too low $(\mathrm{p}=0.002)$.

\section{Discussion}

Generalised low bone mass and osteopenia in the axial and peripheral skeleton have been described in patients with AIS. ${ }^{13-16}$ The precise mechanism of bone loss in these patients in unclear. Recently, many studies have reported that gene polymorphism was related to osteoporosis, but few have linked gene polymorphism and bone mass in AIS. ${ }^{33}$

The IL- 6 receptor gene is one of the candidate genes for osteopenia and osteoporosis. Several genetic association studies with IL-6 receptor polymorphism have yielded different genetic backgrounds. ${ }^{26-28,32-36}$ The allele frequencies of IL6-174 and IL6-597 in Caucasians are much higher than those in Koreans and Chinese, ${ }^{26-28,34-36}$ but the frequency of IL6-572 in Caucasians is much lower than that in Koreans and Japanese. ${ }^{26,27}$ Many studies have 
been conducted regarding IL6-174 in Caucasians; C homozygotes of IL6-174 are associated with lower bone resorption and a smaller decrease in bone mass in older post-menopausal women. ${ }^{31}$ This SNP is also associated with systemic juvenile arthritis ${ }^{37}$ and increased bone resorption. ${ }^{31}$ In pubertal girls, decreased IL-6 may be partly responsible for the development of maximal peak vertebral bone mass. ${ }^{38}$ It was difficult to study the genetic effects of the IL6-174 polymorphism because of its very low frequency in the Korean population. However, the IL6-572 $\mathrm{G} \rightarrow \mathrm{C}$ polymorphism is relatively common in Koreans and Japanese and IL6-572 might therefore be a useful marker for association studies in Asian rather than Caucasian populations, because highly frequent population alleles are particularly useful in mapping those genes responsible for disease susceptibility and other traits.

A study using haplotype analysis is believed to be as effective in determining the genetic contributions of common diseases. The SNPs in the IL-6 promoter region are in complete and/or absolute linkage disequilibrium, so that only three haplotypes (ACC, GCG and GGG) of the possible eight are observed. Generally, haplotypes are more informative than single SNPs, but, the case haplotypes in the IL-6 promoter region, are not informative in association studies of complex trait diseases such as osteoporosis because of the very low frequencies of IL6-597 G $\rightarrow$ A and IL6-174 G $\rightarrow$ C in Asians. ${ }^{26,27}$ Our results also revealed the very low frequencies of IL6-597 G $\rightarrow$ A and IL6-174 G $\rightarrow$ C.

This study examined the IL6-597 G $\rightarrow$ A, IL6-572 G $\rightarrow$ C and IL6-174 $\mathrm{G} \rightarrow \mathrm{C}$ polymorphisms in the IL-6 gene promoter region in order to identify the genes involved in the regulation of bone mass in Korean patients with AIS, who represent an ethnically homogeneous population. We compared the frequencies of genotype in AIS with those in healthy controls and observed a significant difference in the genotype frequencies for IL6-572 $\mathrm{G} \rightarrow \mathrm{C}$ polymorphism, which was associated with lumbar spine BMD in patients with AIS. The prevalence of the three IL6-572 $\mathrm{G} \rightarrow \mathrm{C}$ genotypes in these subjects were GG $62.6 \%$, GC $32.3 \%$ and CC $2.0 \%$. Patients with AIS who had the C allele had a significantly higher lumbar spine BMD but not femoral neck BMD. Our findings are similar to those reported in other studies. ${ }^{26,27}$

There were some limitations to this study. The number of samples tested was relatively small, which diminishes its statistical power and the possibility of detecting correlations. Only some patients had a lumbar curve of $>30^{\circ}$, which can diminish reliability in the measurement of BMD of the lumbar spine. Further studies with a larger and more homogeneous group of patients are recommended. We did not evaluate interactions with other genes, such as the oestrogen receptor gene, or other relevant gene polymorphisms, such as the calcium-sensing receptor gene. The association with other factors, such as the markers of bone metabolism, bone quality and other candidate genes, should also be tested.
We examined the association between BMD and IL6-572 $\mathrm{G} \rightarrow \mathrm{C}$ gene polymorphisms in Korean girls diagnosed with AIS. The IL6-572 G $\rightarrow$ C polymorphism was found to influence lumbar spine BMD, but the definite mechanism for the low bone mass in AIS is unknown.

No benefits in any form have been received or will be received from a commercial party related directly or indirectly to the subject of this article.

\section{References}

1. Ahn UM, Ahn NU, Nallamshetty L, et al. The etiology of adolescent idiopathis scoliosis. Am J Orthop 2002;31:387-95.

2. Ford DM, Bagnall KM, Clements CA, McFadden KD. Muscle spindles in the paraspinal musculature of patients with adolescent idiopathic scoliosis. Spine 1988;13:461-5.

3. Ford DM, Bagnall KM, McFadden KD, Greenhill BJ, Raso VJ. Paraspinal muscle imbalance in adolescent idiopathic scoliosis. Spine 1984;9:373-6.

4. Kindsfater K, Lowe T, Lawellin D, Weinstein D, Akmakjian J. Levels of platelet calmodulin for the prediction of progression and severity of adolescent idiopathic scoliosis. J Bone Joint Surg [Am] 1994;76-A:1186-92.

5. Machida M, Dubousset J, Imamura Y, et al. Pathogenesis of idiopathic scoliosis: SEPs in chicken with experimentally induced scoliosis and in patients with idiopathic scoliosis. J Pediatr Orthop 1994;14:329-35.

6. McCarrey JR, Abbott UK, Benson DR, Riggins RS. Genetics of scoliosis in chickens. J Hered 1981;72:6-10.

7. Stiwell DL Jr. Structural deformities of vertebrae: bone adaptation and modeling in experimental scoliosis and kyphosis. J Bone Joint Surg [Am] 1962;44-A:611-34.

8. Suh KT, Lee SS, Kim SJ, Kim YK, Lee JS. Pineal gland metabolism in patients with adolescent idiopathic scoliosis. J Bone Joint Surg [Br] 2007;89-B:66-71.

9. Wand ED, Drummond DS, Dormans JP, et al. Scoliosis in patients treated with growth hormone. J Pediatr Orthop 1997;17:708-11.

10. Burner WL 3rd, Badger VM, Sherman FC. Osteoporosis and acquired back deformities. J Pediatr Orthop 1982;2:383-5.

11. Singh M, Magrath AR, Maini PS. Changes in trabecular pattern of the upper end of the femur as an index of osteoporosis. J Bone Joint Surg [Am] 1970;52-A:457-67.

12. Cheng JC, Guo X, Sher AH. Persistent osteopenia in adolescent idiopathic scoliosis: a longitudinal study. Spine 1999;24:1218-22.

13. Cheng JC, Qin L, Cheung CS, et al. Generalized low areal and volumetric bone mineral density in adolescent idiopathic scoliosis. J Bone Miner Res 2000;15:1587-95.

14. Cook SD, Harding AF, Morgan EL, et al. Trabecular bone mineral density in idiopathic scoliosis. J Pediatr Orthop 1987;7:168-74.

15. Suh KT, Lee SS, Hwang SH, Kim SJ, Lee JS. Elevated soluble receptor activator of nuclear factor-kappaB ligand and reduced bone mineral density in patients with adolescent idiopathic scoliosis. Eur Spine J 2007;16:1563-9.

16. Thomas KA, Cook SD, Skalley TC, et al. Lumbar spine and femoral neck bone mineral density in idiopathic scoliosis: a follow-up study. J Pediatr Orthop 1992;12:235-40.

17. Cheng JC, Tang SP, Guo X, Chan CW, Oin L. Osteopenia in adolescent idiopathic scoliosis: a histomorphometric study. Spine 2001;26:E19-23.

18. Fang Y, van Meurs JB, Bergink AP, et al. Cdx-2 polymorphism in the promoter region of the human vitamin $D$ receptor gene determines susceptibility to fracture in the elderly. J Bone Miner Res 2003;18:1632-41.

19. Ioannidis JP, Ralston SH, Bennett ST, et al; GENOMOS Study. Differential genetic effects of ESR1 gene polymorphisms on osteoporosis outcomes. JAMA 2004;292:2105-14

20. Murray RE, McGuigan F, Grant SF, Reid DM, Ralston SH. Polymorphisms of the interleukin-6 gene are associated with bone mineral density. Bone 1997;21:89-92.

21. Uitterlinden AG, Burger $\mathbf{H}$, Huang $\mathbf{Q}$, et al. Relation of alleles of the collagen type lalpha1 gene to bone density and the risk of osteoporotic fractures in postmenopausal women. N Engl J Med 1998;338:1016-21.

22. Uitterlinden AG, Pols HA, Burger H, et al. A large-scale population-based study of the association of vitamin $D$ receptor gene polymorphisms with bone mineral density. J Bone Miner Res 1996;11:1241-8.

23. van Meurs JB, Schuit SC, Weel AE, et al. Association of $5^{\prime}$ estrogen receptor alpha gene polymorphisms with bone mineral density, vertebral bone area and fracture risk. Hum Mol Genet 2003;12:1745-54.

24. Roodman GD. Interleukin-6: an osteotropic factor? J Bone Miner Res 1992;7:475-8.

25. Ralston SH. Analysis of gene expression in human bone biopsies by polymerase chain reaction:evidence for enhanced cytokine expression in postmenopausal osteoporosis. J Bone Miner Res 1994;9:883-90. 
26. Ota N, Nakajima T, Nakazawa I, et al. A nucleotide variant in the promoter region of the interleukin-6 gene associated with decreased bone mineral density. J Hum Genet 2001;46:267-72.

27. Chung HW, Seo JS, Hur SE, et al. Association of interleukin-6 promoter variant with bone mineral density in pre-menopausal women. J Hum Genet 2003;48:243-8.

28. Huang $\mathbf{Q Y}$, Shen $\mathbf{H}$, Deng HY, et al. Linkage and association of the CA repeat polymorphism of the IL6 gene, obeisty-related phenotypes, and bone mineral density (BMD) in two independent Caucasian populations. J Hum Genet 2003;48:430-7.

29. Bustamante M, Nogués X, Mellibovsky L, et al. Polymorphisms in the interleukin-6 receptor gene are associated with bone mineral density and body mass index in Spanish postmenopausal women. Eur J Endocrinol 2007;157:677-84.

30. Moffett SP, Zmuda JM, Cauley JA, et al; SOF Research Group. Association of the G-174C variant in the interleukin-6 promoter region with bone loss and fracture risk in older women. J Bone Miner Res 2004;19:1612-18.

31. Ferrari SL, Garnero P, Emond S, et al. A functional polymorphic variant in the interleukin-6 gene promoter associated with low bone resorption in postmenopausal women. Arthritis Rheum 2001;44:196-201.
32. Cheng JC, Guo X. Osteopenia in adolescent idiopathic scoliosis: a primary problem or secondary to the spinal deformity? Spine 1997;22:1716-21.

33. Eun IS, Park WW, Sch KT, Kim JL, Lee JS. Association between osteoprotegerin gene polymorphisim and bone mineral density in patients with adolescent idiopathic scoliosis. Eur Spine J 2009;18:1936-40.

34. Fedetz M, Matesanz F, Pascual M, et al. The -174/-597 promoter polymorphisms in the interleukin-6 gene are not associated with susceptibility to multiple sclerosis. J Neurol Sci 2001;190:69-72.

35. Helmy N, Maly FE, Bestmann L. Detection of the single-base substitution -174 G $\rightarrow C$ in the interleukin-6 gene by real-time polymerase chain reaction: comment on the article by Moos et al. Arthritis Rheum 2001;44:2213-14.

36. Zhai R, Liu G, Yang C, et al. The G to $C$ polymorphism at -174 of the interleukin- 6 gene is rare in a Southern Chinese population. Pharmacogenetics 2001;11:699-701.

37. Fishman D, Faulds G, Jeffrey R, et al. The effect of novel polymorphisms in the interleukin-6 (IL-6) gene on IL-6 transcription and plasma IL-6 levels, and an association with systemic-onset juvenile chronic arthritis. J Clin Invest 1998;102:1369-76.

38. Manolagas SC. The role of IL-6 type cytokines and their receptors in bone. Ann N Y Acad Sci 1998;840:194-204. 